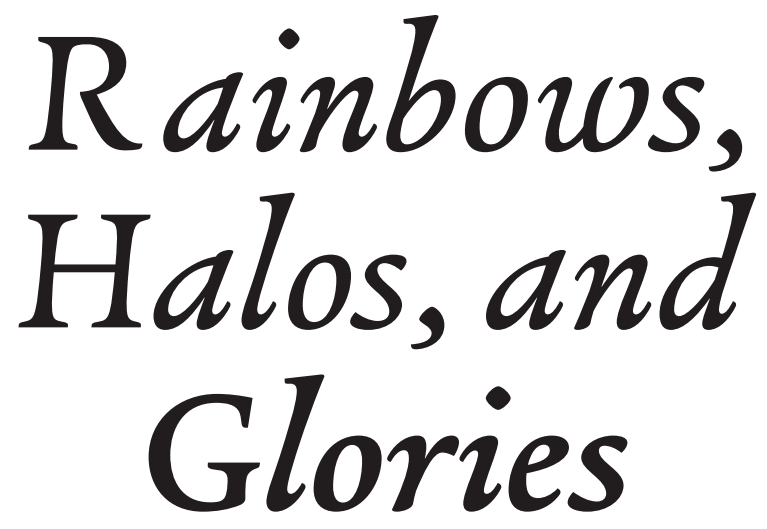


Names: Greenler, Robert, 1929- author.

Title: Rainbows, halos, and glories / Robert Greenler.

Description: Bellingham, Washington : SPIE, [2020]

Identifiers: LCCN 2020031670 (print) | LCCN 2020031671 (ebook) |

ISBN 9781510638372 (paperback) | ISBN 9781510638389 (pdf)

Subjects: LCSH: Meteorological optics. | Rainbows. | Halos (Meteorology)

Classification: LCC QC975.2.G73 2020 (print)| LCC QC975.2 (ebook)|

DDC 551.56/7--dc23

LC record available at https://lccn.loc.gov/2020031670

LC ebook record available at https://lccn.loc.gov/2020031671

Published by

SPIE

P.O. Box 10

Bellingham, Washington 98227-0010 USA

Phone: +1360.676 .3290$

Fax: +1 360.647.1445

Email: books@spie.org

Web: http://spie.org

Copyright (C) 2020 Society of Photo-Optical Instrumentation Engineers (SPIE)

All rights reserved. No part of this publication may be reproduced or distributed in any form or by any means without written permission of the publisher.

The content of this book reflects the work and thought of the authors. Every effort has been made to publish reliable and accurate information herein, but the publisher is not responsible for the validity of the information or for any outcomes resulting from reliance thereon.

Originally printed in 1980 by the Press Syndicate of the University of Cambridge.

First paperback edition 1989

Reprinted 1991, 1994, 2020

Printed in the United States of America.

Fourth printing

For updates to this book, visit http://spie.org and type "PM321" in the search field.

\section{SPIE.}




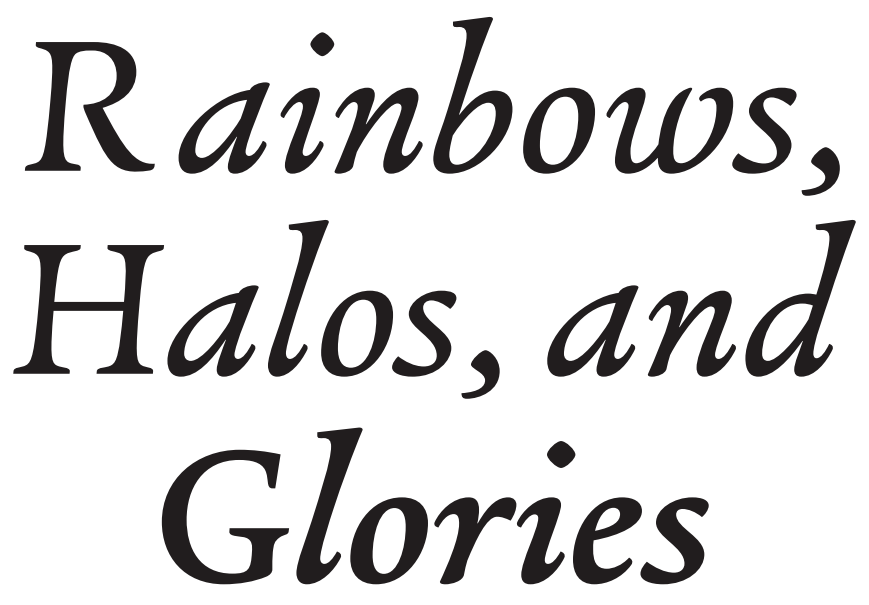

\title{
ROBERT GREENLER
}

\author{
SPIE PRESS
}

Bellingham, Washington USA 
Downloaded From: https://www.spiedigitallibrary.org/ebooks/ on 26 Apr 2023

Terms of Use: https://www.spiedigitallibrary.org/terms-of-use 
Dallas Greenler belped me to view the world of nature with an inquiring mind. John Strong helped me develop the tools of science, to enbance my perception of the world. To them, who taught me the pleasures of seeing with the mind as well as with the eye, I dedicate this book. 
Robert Greenler is an Emeritus Professor of Physics at the University of Wisconsin-Milwaukee, where he has been a faculty member since 1962 . He was instrumental in the development of the Laboratory for Surface Studies at the university.

In 1988, Dr. Greenler received the Millikan Lecture Award from the American Association of Physics Teachers "for creative teaching of physics." He served as president of the Optical Society of America in 1987, and, in 1993, received the Society's first Esther Hoffman Beller Award for "extraordinary leadership in advancing the public appreciation and understanding of science."

In January 1977, Dr. Greenler was at the U.S. Antarctic Research Station at the South Pole studying optical sky phenomena and the ice crystals that cause them. He pursued this research in the Arctic at Point Barrow, Alaska in March 1978 and returned to the South Pole in December 1997, and again in November 1998, to continue this investigation.

Dr. Greenler also has made an important impact on science education. He has taught courses for high school and middle school teachers and has promoted science education in the classroom as well as informal science education for the public. He was the organizer of The Science Bag, a series of public science programs at the University of Wisconsin-Milwaukee. The program is still going on, and nearly 200,000 people have attended the Friday night programs since they began in 1973. If you do a web search for "UWM Science Bag," you can stream several of his video programs, some of which deal with the optical sky effects discussed in the book. 


\section{Contents}

Preface

page ix

I Rainbows

I

2 Ice-crystal refraction effects: halos, arcs, and spots

3 Ice-crystal reflection effects: pillars, circles, and crosses

4 Complex displays, past and present 105

5 Scattering: light in the sky and color in the clouds

I 25

6 Diffraction: the corona, the glory, and the specter of the Brocken

7 Atmospheric refraction: mirages, twinkling stars, and the green flash

Appendix: Answers to puzzles

Notes

General references

Index 
Downloaded From: https://www.spiedigitallibrary.org/ebooks/ on 26 Apr 2023

Terms of Use: https://www.spiedigitallibrary.org/terms-of-use 


\section{Preface}

"Whoever sets pen to paper writes of himself, whether knowingly or not." I suspect that E. B. White's assertion is right. In this book I have chosen, knowingly, to include myself; to include, along with my explanation of the rainbow, my personal delight in seeing it; to share not only the, results of my investigations of ice-crystal halos, but also my excitement in the process of discovery.

The beginning of my interest lies in my childhood awe of the beauty of the rainbow. My response to something that I like is to try to personalize it by my own participation. Photographing these effects is an attempt to possess them, I suppose, and trying to understand their origins is one of my forms of personal participation. Keats, in his poem Lamia, has dealt with the relationship between such understanding and the capacity to appreciate:

There was an awful rainbow once in heaven:

We know her woof, her texture; she is given

In the dull catalogue of common things.

Philosophy will clip an Angel's wings,

Conquer all mysteries by rule and line,

Empty the haunted air, and gnomed mine -

He states, beautifully, an attitude with which I most strongly disagree. For me, understanding enhances the sense of appreciation and wonder. Were I to rewrite Keats, I would, perhaps, end:

To understand and so become aware

And, thus, mine beauty from the crystaled air.

With this book I invite you to invest yourself in further understanding.

The book is also about seeing. The world is full of fascinating things that most of us have never seen - obvious things that exist before our eyes, but that we never see. Again and again I am impressed with our blindness to things, however obvious, that we do not already know of. But the rare trait of looking at the world with 
fresh eyes is one, I believe, that can be fostered and developed. A person who increases the number of areas in which he or she can perceive new things has a source of excitement and satisfaction denied those who do not. This book describes beautiful things that can be seen in the sky, things that can be seen without special equipment or special location, things that can be seen by anyone who sees. I hope that you who read my book will become sensitized to this wealth of sky effects.

My studies of ice-crystal effects (Chapters 2, 3, and 4) have been ongoing over the past dozen years. Much of the work has been done by undergraduate students who became involved and excited by the search for new understanding. Those who have made significant contributions are coauthors of some of the papers listed in the references. However, I want to mention specifically two people who have been major contributors. Jim Mueller became involved as an undergraduate student and continued working with me after he had gone elsewhere to graduate school. Jim Mallmann worked with me on a master's research project that had nothing to do with sky effects; after he graduated he worked with me on understanding sky effects in a fruitful collaboration that has lasted ten years. These people share the credit for many of the results that I refer to as "our work."

Several of the effects illustrated in this book were photographed by me and by others in Antarctica or in the Arctic. Those regions are rich sources of ice-crystal displays that may be seen only rarely in other parts of the world. If we can understand the origins of the optical sky effects, we may use their occurrence and appearance to gain information about atmospheric processes fundamental to the largescale air movements over the entire earth. This is one of the interests of the Division of Polar Programs of the National Science Foundation, who made it possible for me to go to the ends of the earth to study these effects. I acknowledge their support with thanks.

R.G. 


\section{Preface Addendum}

This volume was originally published 40 years ago, and it has been out of print for several years. I still get an occasional letter from someone who has just "discovered" the book and is enthusiastic about its contents. More often, I hear from people who are excited to have seen some beautiful effect in the sky and are delighted to understand its origin by looking at this book, which sits on their shelf.

We have decided to publish this edition without changes. Of course, since the original publication date, there has been increased understanding of some of the effects, and many more excellent color photos are now available. Nevertheless, I hope that the historical introduction and intuitive explanation of these effects will continue to excite and inform new readers of the beauty available to anyone who looks skyward with an inquiring eye.

A note concerning the ancient history of computer technology that is illustrated in this volume: When we first started doing the computer simulations - displayed as dot diagrams in this book — we created a deck of punched IBM cards, which constituted the computer program. This deck of cards was sent off by a daily van service from Milwaukee to Madison, where the main computer was located. An all-too-frequent next step was to have the stack of cards returned with a note that there was an error on card \#372. Try again. After a successful run, the results were printed out on the 36-inch-wide sheet of paper of the wet-ink chart recorder we had in Milwaukee. Any of the more complicated displays might take an hour or more to plot, and there was a queue for people signed up to use the plotter. With this system, we would see the results of an idea for explaining the circumzenithal arc, for example, a minimum of 3 or 4 days after writing the program. As we persisted, the computing methods improved, but each of the simulations done in this book was made by photographing the large plots made on the wet-ink chart recorder. Even I, who was there, am amazed that we were able to produce these results with such "stone-age" technology.

I repeat my exhortation to the reader to develop the habit of looking at the world with fresh eyes - to search for the story behind the first visual impression - to see with the mind as well as the eye.

Robert Greenler, 2020 
Downloaded From: https://www.spiedigitallibrary.org/ebooks/ on 26 Apr 2023

Terms of Use: https://www.spiedigitallibrary.org/terms-of-use 